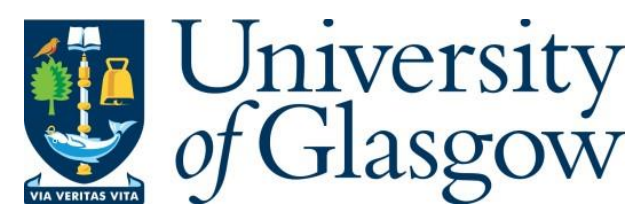

Mellor, A. et al. (2016) Specially Designed Solar Cells for Hybrid Photovoltaic-thermal Generators. In: IEE 43rd Photovoltaic Specialist Conference (PVSC), Portland, OR, 510 June, 2016, pp. 2960-2963. ISBN 9781509027248.

There may be differences between this version and the published version. You are advised to consult the publisher's version if you wish to cite from it.

http://eprints.gla.ac.uk/142106/

Deposited on: 26 September 2017

Enlighten - Research publications by members of the University of Glasgow http://eprints.gla.ac.uk 


\title{
Specially designed solar cells for hybrid photovoltaic-thermal generators
}

\author{
Alexander Mellor ${ }^{1}$, Ilaria Guarracino ${ }^{2}$, Lourdes Ferre Llin $^{3}$, Diego Alonso-Alvarez ${ }^{1}$, Alberto Riverola ${ }^{4}$, \\ Stephen Thoms ${ }^{3}$, Douglas J. Paul ${ }^{3}$, Christos N. Markides ${ }^{2}$, Daniel Chemisana ${ }^{4}$, Stefan Maier ${ }^{1}$, Ned Ekins- \\ Daukes $^{1}$ \\ ${ }^{1}$ Department of Physics, Imperial College London, London SW7 2AZ, United Kingdom \\ ${ }^{2}$ Department of Chemical Engineering, Imperial College London, London SW7 2AZ, United Kingdom \\ ${ }^{3}$ School of Engineering, University of Glasgow, Glasgow G12 8LT, United Kingdom \\ ${ }^{4}$ Applied Physics Section of the Environmental Science Department, University of Lleida, 25001 Lleida, Spain
}

\begin{abstract}
The performance of hybrid photovoltaic-thermal systems can be improved using PV cells that are specially designed to generate both electricity and useful heat with maximum efficiency. Present systems, however, use standard PV cells that are only optimized for electrical performance. In this work, we have developed two cell-level components that will improve the thermal efficiency of PV-T collectors, with minimal loss of electrical efficiency. These are a spectrally-selective lowemissivity coating to reduce radiative thermal losses, and a nanotextured rear reflector to improve absorption of the nearinfrared part of the solar spectrum for heat generation.
\end{abstract}

\section{INTRODUCTION}

A key advantage of solar energy is the ability to generate electricity in the urban and build environment. This has the benefit of moving generation closer to the point of use, therefore reducing the demand on the costly energy distribution infrastructure, and reducing the need for largescale solar plants supplanting farmland. In urban areas, population is dense and real estate expensive. Hence, in order to maintain a low cost per kilowatt hour of solar energy generation, it is necessary not only that the solar energy generators be low cost, but that the maximum amount of highquality energy be generated per $\mathrm{m}^{2}$ of roof coverage. This requirement can be best met by hybrid photovoltaic-thermal (PV-T) systems [1], which generate both electricity and useful thermal energy from a single aperture area. Significant advances, however, are required both at the cell and generator/system levels for PV-T systems to be competitive. Both the electrical and thermal efficiency must be increased, and the thermal energy must be delivered at a much higher temperature to increase the utility. In this work, we develop custom-built PV cells for use in PV-T systems that satisfy these demands, and investigate their impact on the thermal and electrical efficiency of PV-T generators.

Typically, PV-T generators use the same PV cells that are used in conventional non-hybrid PV panels. These cells are optimized for electricity generation, but not for heat generation. Thermal radiation from the PV cell limits the thermal efficiency, particularly if the generator is to deliver high-temperature heat, as is required for applications such as space heating or absorption cooling. Furthermore, the absorption of the part of the solar spectrum corresponding to below-bangap-energy photons $(1100-2500 \mathrm{~nm})$ is nonoptimal, since these contribute to heat generation but not to electrical output. This is particularly true of heterojunction solar cells due to their lack of a highly doped emitter; heterojunction cells would otherwise be promising for hightemperature PV-T due to their low temperature coefficient.

In this work, we have developed a spectrally-selective low-emissivity coating for c-Si solar cells, and a nanostructured rear texture to effectively absorb light in the $1100-2500 \mathrm{~nm}$ range, both have the potential to improve the thermal efficiency of PV-T systems without significantly compromising the electrical efficiency.

\section{A SPECTRALLY-SELECTIVE LOW-EMISSIVITY COATING FOR C-SI SOLAR CELLS}

Both in PV-T and conventional solar thermal systems, there is a trade-off between thermal efficiency and the temperature of heat extraction, since removing more heat decreases temperature. This is demonstrated in Fig. 1 (yellow curve), which is calculated using a simple thermodynamic model that assumes the only heat loss is radiative emission. In a conventional thermal collector, high thermal efficiencies can be maintained at high temperatures due to the use of evacuated tubes to control convective loss, and the presence of a selective surface, which suppresses the radiative thermal emission. The latter is illustrated in Fig. 2, where the absorber has high absorptivity (and emissivity) throughout the visible portion of the solar spectrum but low emissivity at wavelengths beyond $2.5 \mu \mathrm{m}$, at which thermal emission occurs. The blue curve in Fig. 1 shows the dramatic increase in absorber temperature that can be achieved using a selective surface. Importantly, temperatures in excess of $100^{\circ} \mathrm{C}$ can be obtained whilst removing up to $800 \mathrm{~W} \mathrm{~m}^{-2}$ as useful heat, whereas only $200 \mathrm{~W} \mathrm{~m}^{-2}$ can be extracted at the same temperature without a selective surface.

Evacuated tubes are now being used in PV-T generator designs[2]; however, the use of selective surfaces is absent, due to their reliance of PV-T generators on conventional PV cells. This is addressed in this work. 


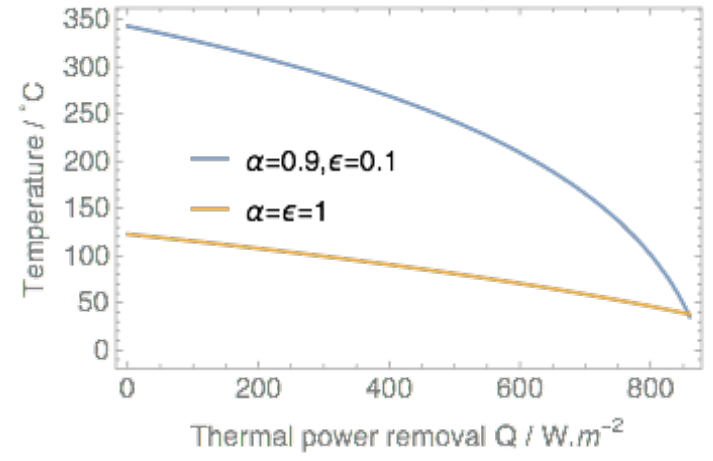

Figure 1. Absorber temperature Vs thermal power removal for a blackbody absorber $(\alpha=\varepsilon=1)$ and a selective surface $(\alpha=0.9, \varepsilon=0.1)$.

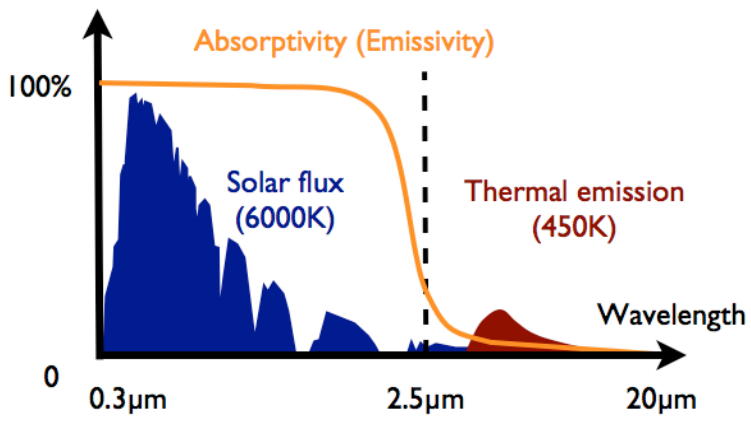

Figure 2. Absorptivity profile for a selective surface, with strong absorptivity at short wavelengths where the solar flux is high and low emissivity at longer wavelengths where thermal emission takes place.

Silicon solar cells are expected to be highly emissive in the infrared region of the spectrum due to free carrier absorption in the highly doped emitter and light-outcoupling by the surface texture[3]. The emissivity can be supressed using a coating that is reflective at thermal-emission wavelengths $\left(3-20 \mu \mathrm{m}\right.$ for a body at $\left.100^{\circ} \mathrm{C}\right)$, but transmissive at solar wavelengths $(300-2500 \mathrm{~nm})$. This property is exhibited by $\operatorname{In}_{2} \mathrm{O}_{3}$ : Sn (ITO) films, which are typically used in energy-efficient windows for this purpose[4, $5]$.

ITO films with $100 \mathrm{~nm}$ thickness were deposited on polished silicon wafers, and on pieces of commercial c-Si solar cells with areas around $2 \times 2 \mathrm{~cm}^{2}$. The films were RF sputtered at a substrate temperature of $250{ }^{\circ} \mathrm{C}$, a deposition rate of $0.07 \mathrm{~nm} / \mathrm{s}$, an argon pressure of $2.5 \mathrm{mTorr}$, and without the presence of oxygen, following Ref. [6]

The reflectivity of the polished wafer before and after applying a coating with ITO was measured over the $3-16 \mu \mathrm{m}$ wavelength range using a FTIR spectrometer. This is shown in Figure 3. It can be observed that the ITO film increases the reflectivity from $20 \%$ to $85 \%$ at a wavelength of $12 \mu \mathrm{m}$, which corresponds to the emission peak of a black-body at $100^{\circ} \mathrm{C}$. This suggests that the ITO coating can efficiently suppress radiative thermal emission of c-Si solar cells at the operating temperatures of $\mathrm{PV} / \mathrm{T}$ collectors.

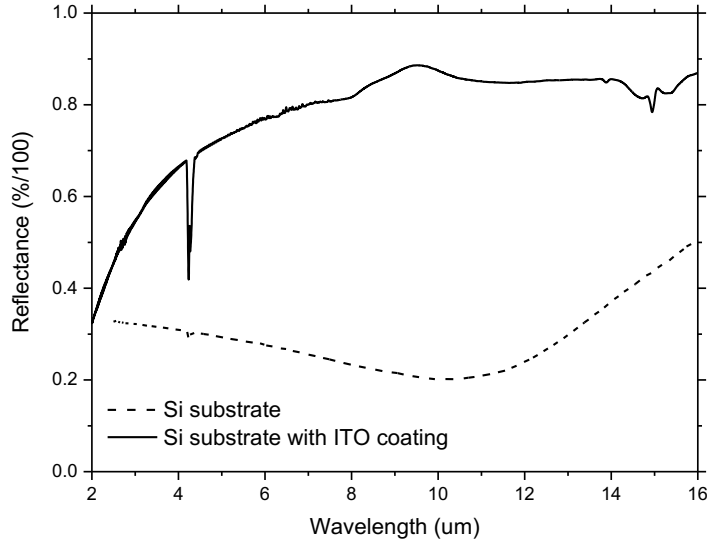

Figure 3. The MIR reflectivity of c-Si wafers with and without an applied ITO coating.

The reflectivities of the ITO coated solar cells must be measured using an integrating sphere due to their surface texture, this will be performed in future work.

Light-IV measurements were taken under an AM1.5 spectrum $\left(1000 \mathrm{Wm}^{-2}\right)$ using a TS-Space systems Unisim solar simulator, both before and after coating. The light-IV curves and characteristics are presented in Figure 4. It can be observed that the presence of the ITO film leads to a relative $3 \%$ reduction in the $I_{s c}$, which is attributed to reduced transmission into the solar cell due to the reflection/absorption of the ITO film. No significant drop in $V_{o c}$ or $F F$ is observed. The relative drop in power output is $3 \%$ corresponding to an absolute efficiency reduction of $0.5 \%$. This loss in electrical efficiency is an unwanted cost of improving thermal efficiency via the low emissivity coating. Further optimisation of the ITO film, either by improving film quality or optimising the film thickness is expected to reduce this loss.

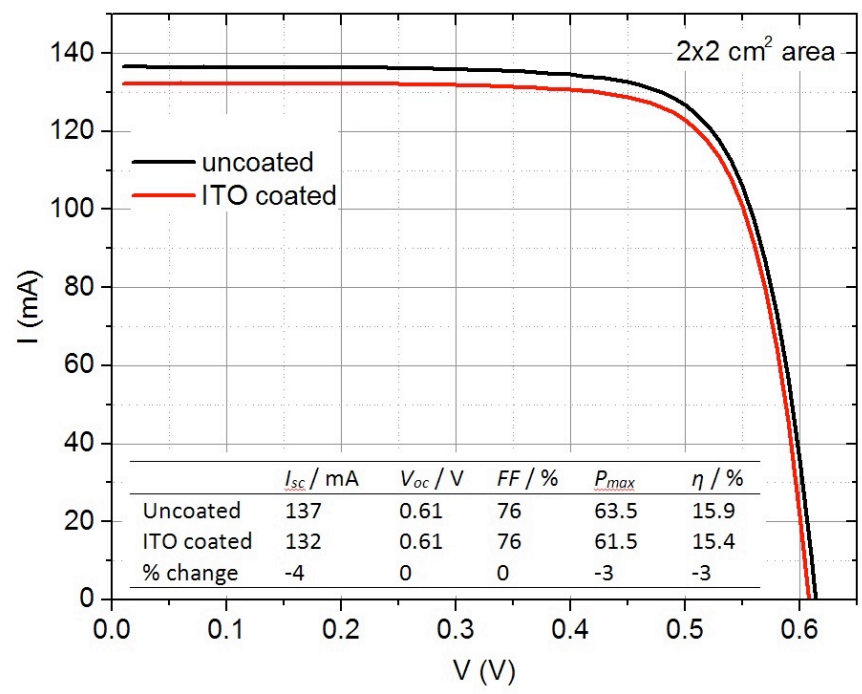

Figure 4. Light IV curve of a $2 \times 2 \mathrm{~cm}^{2}$ piece of commercial c-Si solar cell measured under an AM1.5 spectrum before and after the application of the ITO coating. 


\section{NANOSTRUCTURED REAR TEXTURE FOR OPTIMUM ABSORPTION OF NEAR-INFRARED SOLAR RADIATION}

Heterojunction solar cells are promising candidates for high-temperature PV-T collectors due to their low temperature coefficient [7]. Due to the lack of a highly doped emitter region, however, they are not expected to strongly absorb the near-infrared (NIR) part of the solar spectrum ( $1100-2500$ $\mathrm{nm}$ ). This corresponds to $20 \%$ of the incident radiation, meaning that an absolute $20 \%$ improvement in thermal efficiency could be achieved if it is effectively absorbed and converted to useful heat.

We have developed a rear surface texture that will allow this radiation to be absorbed in the rear reflector of the device. It is known that a textured metal surface can be highly absorbing due to the generation of surface plasmons [8]. To demonstrate this, we demonstrate in Figure 5 the calculated power absorption in a planar $\mathrm{Al} / \mathrm{Si}$ interface and a textured $\mathrm{Al} / \mathrm{Si}$ interface, along with the illuminating AM1.5G spectrum. The texture is a periodic binary grating with a 450 $\mathrm{nm}$ period, the absorption of which has been calculated using rigorous coupled wave analysis (RCWA). In this example, 80 $\mathrm{W} \mathrm{m} \mathrm{m}^{-2}$ is absorbed in the textured rear contact, to be compared to $16 \mathrm{~W} \mathrm{~m}^{-2}$ for the planar case. This corresponds to a thermal efficiency enhancement of around 5\% absolute, which we expect to be significantly improved upon when optimized.

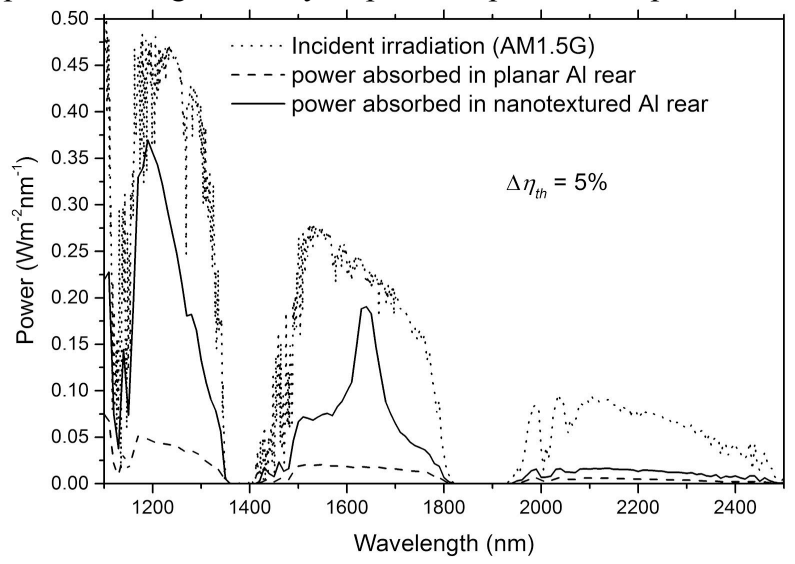

Figure 5 Dotted line: AM1.5G spectrum for energies below the c-Si bandgap. Dashed line: Power absorbed in a planar Al rear contact. Solid line: Power absorbed in a nanotextured $\mathrm{Al}$ rear contact.

PV cells typically employ pyramidal surface textures with scales on the order of $10 \mu \mathrm{m}$ for anti-reflection and light trapping purposes. To investigate the effect of a rear-side nano-texture in a structure that also has a front-side micronscale texture, c-Si wafers have been textured with both front and rear side textures by e-beam lithography. Samples were prepared with different combinations of textures, shown schematically in Figure 6. SEM micrographs of the pyramid and nanopillar textures are presented in the top and bottom panels Figure 7 respectively; they have periods of $20 \mu \mathrm{m}$, and $500 \mathrm{~nm}$, respectively. The absorption of these samples in the $1100-2500 \mathrm{~nm}$ wavelength range will be measured using an integrating sphere in future work.

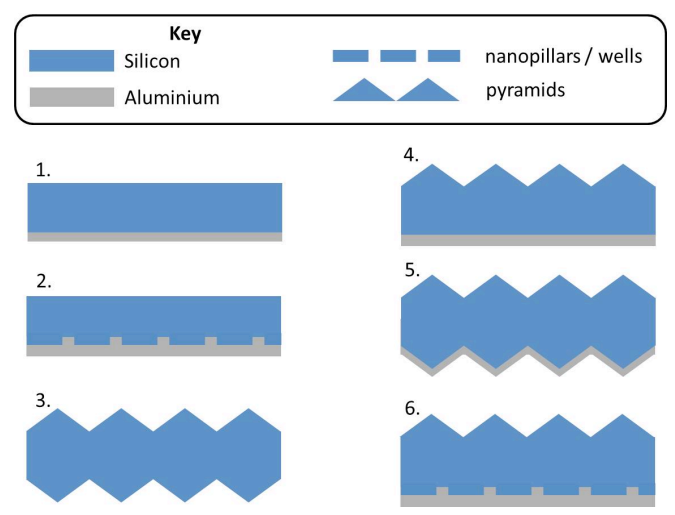

Figure 6. Configurations of surface textures studied in this work
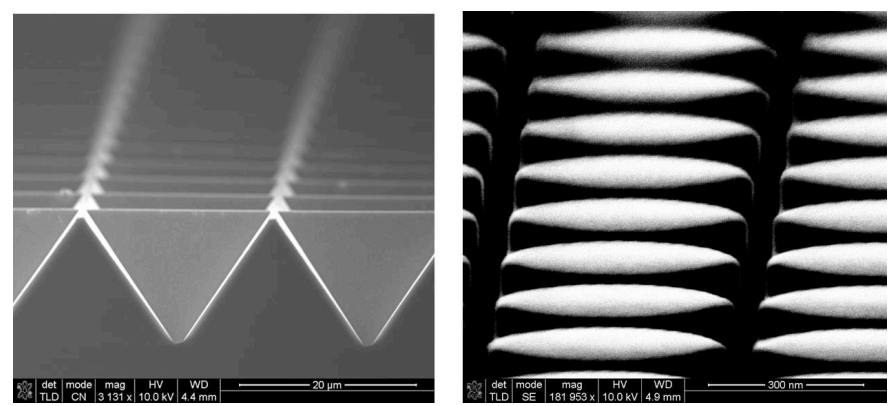

Figure 7. SEM images of the surface pyramids (left) and the nanopillars (right)

\section{REFERENCES}

[1] H.A. Zondag, Flat-plate PV-Thermal collectors and systems: A review, Renewable and Sustainable Energy Reviews, 12 (2008) 891-959.

[2] http://www.nakedenergy.co.uk/product/how-it-works/, in.

[3] R. Santbergen, R.C. van Zolingen, The absorption factor of crystalline silicon PV cells: a numerical and experimental study, Solar Energy Materials and Solar Cells, 92 (2008) 432444.

[4] I. Hamberg, C.G. Granqvist, Evaporated Sn - doped In2O3 films: Basic optical properties and applications to energy efficient windows, Journal of Applied Physics, 60 (1986) R123-R160.

[5] A. Solieman, M.A. Aegerter, Modeling of optical and electrical properties of In 2O3:Sn coatings made by various techniques, Thin Solid Films, 502 (2006) 205-211.

[6] T. Ocal, S. Yusuf, A. Gulnur, O. Lutfi, High quality ITO thin films grown by dc and RF sputtering without oxygen, Journal of Physics D: Applied Physics, 43 (2010) 055402.

[7] T. Mishima, M. Taguchi, H. Sakata, E. Maruyama, Development status of high-efficiency HIT solar cells, Solar Energy Materials and Solar Cells, 95 (2011) 18-21.

[8] J. Springer, A. Poruba, L. Mullerova, M. Vanecek, O. Kluth, B. Rech, Absorption loss at nanorough silver back 
